\title{
On the Use of Automatic Speech Recognition to Facilitate Increased Literacy Rates in Jamaica
}

\author{
André Coy \\ Department of Physics \\ University of the West Indies, Mona, Jamaica
}

\begin{abstract}
This paper makes the case for the use of automatic speech recognition (ASR) in addressing the issue of increasing the rates of literacy of children in the developing world, using Jamaica as a test case. It gives an overview of the current state of affairs, which underscores the need for developing innovative ways of delivering literacy education. Following a review of the state of the art in ASR-based literacy tutors, the technical and pedagogical challenges of developing such a system for Jamaica are discussed.
\end{abstract}

\section{Introduction}

Literacy plays an important role in the creation of functional individuals, as well as in the development of strong economies [1]. Thus, it is imperative that literacy education is seen as a priority, especially in developing countries. However, with the advent of the global economic crisis, many governments worldwide have had to reduce their budgets for education at all levels, including teacher training. These cuts have affected developing countries more significantly than they have countries in the developed world. A recent report by the United Nations Educational, Scientific and Cultural Organization (UNESCO) has indicated that one of the possible consequences of these measures is a reversal of the hard-fought gains achieved in education over the past decade [2]. The countries of the Caribbean are among those that can be so affected. This of course, has implications for the region's overall capacity for economic growth and human development. Particularly as the number of literacy specialists decrease and class sizes increase, it is becoming increasingly difficult to give individualised attention to struggling readers.

Given these and other challenges that are faced by practitioners and administrators in the education system, new methods of teaching literacy need to be developed. In addition to this, the changing needs of modern learners in a digital age must be addressed. Even more, traditional teaching techniques are limited in the numbers of students they can reach, especially in an environment where individual attention is not always possible, mostly because of large class size. This can have significant ramifications, since each learner has unique challenges and it is easy for slow readers to fall behind. The use of technology is central to these most urgent tasks [3].

What follows is a discussion of one approach that would provide a powerful tool to teachers of literacy in Jamaica. This technology-based approach to teaching literacy will go some way to overcoming some of the difficulties faced by practitioners when employing traditional methods. The proposed solution takes advantage of the most natural modality for human communication, speech, and builds upon this to develop a literacy tutor based on automatic speech recognition (ASR). Such an approach provides an opportunity to design a purpose-built solution to the problem of increasing literacy rates in Jamaica and potentially other developing countries. The remaining sections discuss the benefits and challenges of developing an ASR-based literacy tutor (ALT) for use in Jamaican schools. The rest of the paper is structured as follows. Section 2 discusses the current state of child literacy in Jamaica. Section 3 will explore the ASR-based computer assisted language learning (CALL) systems and their role in automated reading tutors. Section 4 reviews currently implemented ALTs. In Section 5 a discussion of the benefits and challenges of developing and implementing such a system in Jamaica is presented. The paper concludes in Section 6.

\section{Child Literacy in Jamaica}

One Millennium Development Goal (MDG) is the maintaining or surpassing of current levels of literacy worldwide. There has previously been a commitment by Jamaican authorities to meet the MDG of having $100 \%$ youth literacy by 2015 [4]. In an effort to 
achieve this, the number of literacy specialists, acting as advisors to teachers, was increased from 50 in 2009 to 90 in 2010 . However, current results suggest that while some progress has been made, a lot more needs to be done. This is evident from Figure 1, which shows the performance of students at the Grade Four Literacy Test (GFLT). The GFLT has become the main focus of the Ministry of Education toward improving literacy, in particular, and quality of education in general [5]. In 1999, the first year of testing, the percentage of mastery was $52 \%$. The percentage of students attaining mastery in 2011 was $71 \%$, an increase over the result of the previous year.

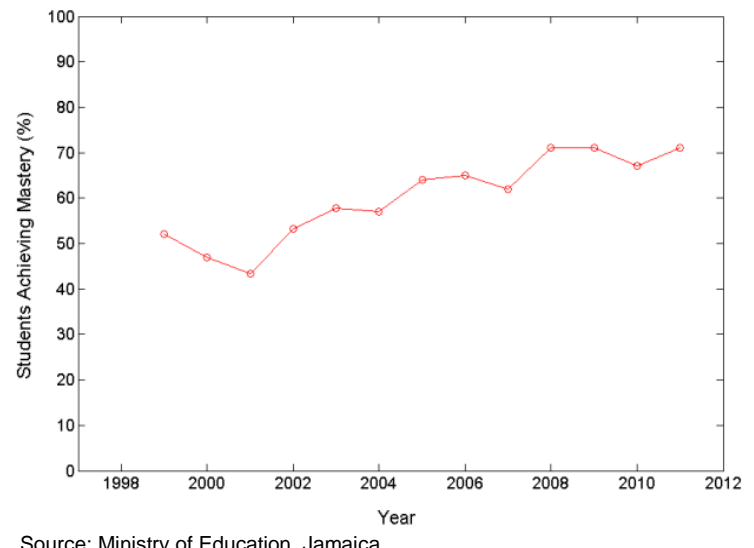

Figure 1. Performance of students at the GFLT

These figures however, show that 3 in 10 children in Jamaica, at the grade four level, are illiterate. Given the current rate of increase, it would take approximately 19 more years to achieve full literacy of primary school-aged children.

In the past decade there have been no fewer than nine major initiatives, funded by government and multi-national agencies, aimed at reforming primary school education and thus, improving literacy and numeracy among Jamaican children [6]. These have no doubt borne fruit, as is evidenced by the increased rates of mastery of the GFLT. They have however, generally made limited use of technology as a way of enhancing instruction, reducing teacher workload and limiting teacher intervention in literacy education. This is an important consideration, given that Jamaica has the highest pupil to teacher ratio in the Caribbean, with 27.7 pupils to each teacher [7]. Along with the initiatives of the government, there are also initiatives by multi-national companies to increase rates of literacy in the island [8].

Not only is there a challenge when young learners get to school, but there is also a deficit in at-home preparation for reading. Research has shown that it is useful for young learners to be partially prepared at home, by being read to and being taught how to read, before entering the formal education system [9]. However this does not always happen; and it is less likely to happen in low-income families [10]. Among the reasons shown for the lack of time spent reading to children in low-income homes is the lack of access to resources (books and money to buy books) and the ability of the mother to read [11]. Many children from low-income families are not being exposed to reading or literacy related activities at an early age and thus fail to benefit from the attendant advantage this provides. Given that many learners are entering the classrooms with little in the way of exposure to reading and literacy related activities, there is a pressing need for programmes that allow for individualised attention at some level during the first few years of schooling. This cannot be achieved with sole reliance on traditional approaches.

Adult literacy is also a cause for concern, as there is a knock-on effect from the deficit seen in child literacy. The latest available statistics from UNESCO place Jamaica at $22^{\text {nd }}$ out of 28 countries in the Latin American and Caribbean region. Jamaica has an average adult literacy rate of $86.4 \%$, almost five percentage points lower than the regional average.

Thus, the environment is one of progress tempered by significant challenges. If full mastery for all students is to be achieved in time to meet the MDG commitment, a radical new approach will have to be taken in order to augment the approaches currently employed in teaching literacy.

\section{Computer Assisted Language Learning}

Computer assisted language learning broadly refers to the use of computer hardware and software to facilitate the learning of a language. Though traditionally envisioned for second language learning, it is now understood that CALL encompasses both first (L1) and second (L2) language learning. The current work looks beyond the narrow focus of second language learning to focus on the development of early reading skills by learners who are already familiar with the language of instruction but have yet to develop the skills such as decoding and reading fluency. Blok et al. [12] reviewed 42 research articles and concluded that CALL systems focusing on early reading skills had a small, but statistically significant, positive effect on users. A meta-analysis of hundreds of studies of L1 and L2 CALL systems showed consistent positive benefits for CALL systems focusing on L1 reading, writing and spelling; there was no such finding for L2 systems [13]. These and other studies suggest that CALL aids have the potential to augment traditional teaching techniques 
and even replace them in certain controlled circumstances [14]. The dramatic increase in processing power, low cost of computer equipment and software, as well as the fact that learners can be easily motivated to use computers, make this type of solution extremely attractive for teachers of languages.

Warschauer [35] refers to three different stages in CALL system development: Structural, Communicative and Integrative CALL. This categorisation is not universally accepted but it serves as a useful guide. The first CALL systems developed in the 1960s and 70 s are referred to as structural systems - these systems are also referred to as Behavioural systems because of the emulation of the techniques of structural linguistics. This meant that these systems used the computer for drills and concentrated on the accuracy of reproduction. The change in CALL development came with a paradigm shift in theories of language learning. In the early 80 s the cognitive view of language became predominant and CALL systems followed suit. These communicative CALL systems involved one-way communication, where in an effort to increase fluency, the users were given exercises in which they practiced repeating the output of the system. This type of CALL dominated until the end of the 90s. What followed was the integrative approach, which allowed users to engage in more authentic social interaction, giving them the opportunity to become more directly involved in the language learning process. Previous systems focused mainly on recall and accuracy. The integrative approach, with its emphasis on real-life social interaction made the language learning experience more rewarding and useful for the learner.

Because of the broad definition of what a CALL system is, CALL can be facilitated by the use of either generic or purpose built software [36]. In the case of generic software, CALL approaches take advantage of the functionality of existing software applications (for example, word processing tools and web browsers). With CALL specific software there is a focus on the development of tools that are specifically designed for the purpose; these tools most often take advantage of prevailing theories of language learning. Gündüz [36] summarises the pros and cons of traditional CALL systems, some of which are listed below:

\section{Advantages}

- Individualised attention

- The computer can act as a guide

- Computers offer some level of interaction

- Different speeds of learning can be accommodated

- Multi-modal practice with feedback

- Computer literacy

\section{Disadvantages}

- Learners work in isolation

- The computer cannot deal with the unexpected

- Feedback is limited

- Computers cannot conduct open-ended dialogues

Historically, CALL systems were criticised for lacking feedback and thus, not being truly interactive. They therefore, did not provide an authentic language learning experience. However, recent advances have allowed for improvements that have led to these approaches being considered, in some spheres, to be cost-effective alternatives to employing experts to provide individual attention to learners [17].

While CALL systems take many different forms, one of the most rapidly expanding areas involves tools that make use of spoken language technology for education, so called, SLATE systems. Though SLATE systems have predominantly been employed for second-language learning, they are increasingly being seen as useful tools in first language training and the development of overall literacy skills [18, 21]. Modern SLATE tools, such as automated reading tutors are advantageous because of the fact that they listen to the reader and provide interactive feedback, similar to that provided by a trained human expert.

Crucial to the success of this type of CALL system is the inclusion of ASR technology. ASR is becoming ubiquitous, from the voice dialling function in mobile phones, to dictation software and medical transcription devices. Speech is the most natural form of communication for human beings; it follows then, that technology which exploits this mode of transmitting information will have a significant impact on society; especially where tools are developed to simplify everyday tasks. ASR technology readily allows for the development of aids in which two-way interaction is achieved. An automatic reading tutor that listens to the user and provides useful, real-time feedback is more likely to replicate the experience of having a one-to-one session with a literacy specialist $[17,20]$. Among the potential gains is the fact that users would have multiple modes of stimulation, which holds the potential to enhance the effectiveness of the lesson. A further benefit is that the tool can be customised to meet the individual needs of readers, diagnose specific difficulties and track the progress of users over time.

\subsection{ASR and Automated Tutors}

It is well understood that one of the most important techniques for developing fluency and increas- 
ing comprehension in readers is one-to-one reading with a dedicated instructor [20]. The effect of individualised attention is so significant that improvements can be seen even where the instructor is not a trained professional. When a reader works with a competent guide there are a multitude of benefits that accrue. The fact that tutoring sessions are one-to-one provides the reader with a sense of security, which would not be achievable in an open classroom reading situation. The positive feedback and support (both emotional and subject specific) received from a competent tutor makes the experience a positive one, allowing the reader to focus on the lesson. Research has shown that in order to design a reading programme, consisting of traditional techniques, and achieve the same effectiveness as one-to-one tutoring, the programme would have to be made up of several different components and would require the co-operation of teachers, parents and the learners' peer group [37]. Clearly this type of approach is too complex and resource intensive especially in the context of a developing country. Further, the logistics and expense involved in providing opportunities for each student in a classroom to have one-to-one reading sessions severely limits the availability of these programmes. Thus an alternative approach that is less resource intensive has to be found.

\subsection{Computer-based Tutoring Systems}

The field of computer assisted language learning has been around for some time. However, the inclusion of some aspects of Artificial Intelligence was first seen as viable less than two decades ago (see [14], for a review of the evolution of Intelligent CALL). Since then a variety of systems have been proposed and implemented, with some being converted into commercially available software. One of the drawbacks of these systems, however, was seen to be their inability to mimic the experience of having a tutor providing useful feedback. In order for these systems to potentially provide such an experience, they must be able to process spoken input.

Thus, the inclusion of speech recognition modules in intelligent tutoring systems heralded a new era for language learning technologies. ASR technology provides the platform for developing automated language tutors that can listen to the users' speech, analyse it for errors, provide feedback - immediately through the highlighting of the error, or delayed, where errors are stored for future analysis. The technology also allows for directed practice sessions, where readers can work on different skills, including word recognition, decoding and the pronunciation of certain words or phonemes.

In order to perform the tasks required, the systems broadly consist of three modules: an ASR module for listening - detecting and recognising the readers' speech - a speech synthesis module for giving feedback and reading aloud to the user and a module for managing dialogue so that interactions appear as natural as with a human tutor. In order to be considered acceptable by users and experts, all three modules must have a high level of accuracy. Otherwise, the tool loses its usefulness, as either frustration will occur or the reader will not be corrected when they ought to be, thus reinforcing the incorrect practices such as poor pronunciations or ungrammatical sentences. Dialogue management systems are employed to coordinate the jobs of the speech synthesis and recognition modules. In the past the lack of robust dialogue management systems was seen as a weakness of ASR-based tutoring systems; however, more recent systems have been significantly improved allowing for the development of more sophisticated tutoring systems.

\section{ASR-based Literacy Tutors}

This section gives an overview of the state-of-theart in ALTs (a full review is beyond the scope of this work, for comprehensive coverage see [15]).

ALT systems began to appear as early as 1992. McCandless for example, developed an ALT, where the user read a text shown on the computer screen and the tutor listened and provided feedback on what was said [16]. Another approach, Project LISTEN worked as a tutor by listening to, as well as reading to the user [17]. This system was one of the first to employ feedback that was able to effectively respond to readers when they encountered challenges or made mistakes. When the system was deployed in schools it was found that students using the reading tutor outperformed their peers who learned from regular classroom-based activities and compared favourably to students given one-to-one tutoring by human experts. The STAR system was another early system that was also deployed in schools and met with favourable responses by both readers and teachers [18].

The Foundations to Literacy programme from the University of Colorado was developed as a reading tutor for emerging readers as one component of the Colorado Literacy Tutor (CLT) [19]. Owing to its effectiveness, several schools in Colorado have adapted their approach to teaching literacy in order to accommodate the programme in their classrooms.

Insights Reading Fluency was developed with both students and teachers in mind [20]. Trials in schools showed that the students using the tutor exceeded their expected fluency gain targets.

The majority of research done on ASR-based tu- 
tors has involved the teaching of English; however, several systems have also been developed for other languages. One recent system, the SPACE tutor was developed to deal with the limitations faced by Dutch elementary schools in providing individualised reading tuition to elementary school children [21]. Other non-English systems include DISCO for Dutch users [22] and the Italian Literacy Tutor, for Italian readers using the CLT as a model [23].

In addition to the research systems discussed above, there are also commercial systems such as Fast Forward and the Reading Companion by IBM [24]. Microsoft has also made efforts to develop an automatic reading tutor to be deployed on hand-held devices [25].

\section{A Jamaican ASR-based Literacy Tutor}

Section 4 reviewed previously implemented ASRbased tutoring systems in the teaching of literacy. The projects highlighted (with the exception of the IBM Reading Companion) have been deployed for use in the developed world where there is generally more focus on, and funding for research into the development of innovative teaching techniques. Where real-world studies have been carried out, they have shown that ALTs can enhance the teaching of literacy and benefit students that would otherwise not have been able to make the most of their studies because of illiteracy. Following from this, it is being suggested here that there is value in creating such a system in the developing world. This section will explore some of the benefits associated with such an effort for the developing world using Jamaica as an example. Where challenges exist, those will be discussed and possible solutions put forward.

The use of Jamaica as a case study for this paper is motivated by a number of factors, none of which are unique to Jamaica, but which pose a more significant challenge given the countries current socioeconomic status. Among the challenges affecting the delivery of literacy education in Jamaica currently are:

- Low levels of trained teachers, especially at the early childhood level;

- Negligible use of technology at all levels;

- Inadequate funding for schools;

- Inequality between schools in their facilities and abilities to deliver programmes;

- Inability to retain trained teachers owing to recruitment overseas;

- More money is being spent on top performing schools as opposed to those that most need assistance;

- The highest pupil to teacher ratios in the Caribbean;
- Reduction in expenditure (as a percentage of GDP) on education;

- Among the lowest expenditure on primary education as a percentage of total expenditure on education;

These and other factors make Jamaica a good candidate for use in this case study.

\subsection{Benefits}

The use of an ALT in the Jamaican context can compensate for some of the challenges that are faced by literacy teachers and students alike. Students are likely to be more readily engaged and their attention held for longer when using tools that allow for twoway interaction in the way that may be possible with an ASR-enabled tutor.

For struggling readers that are at risk of falling behind, the technology allows them to work at their own pace, adapting to their proficiency level, without having an impact on the rest of the cohort. This can have a positive effect on students at risk of falling behind, as it has been shown that there is great difficulty in closing the gap when students do fall behind [26]. This potentially, has significant consequences for Jamaica, as research has generally shown failure to close the gap and achieve literacy in childhood being linked to failure in adulthood for individuals from poor socio-economic backgrounds [27].

An ALT, with its ability to listen to the reader, can provide useful feedback or correction where necessary. Errors made while reading can be immediately identified and the information stored for use in structured practice sessions. Reading aloud to the tutor, as opposed to spontaneously in a classroom setting, can have significant benefits, including increased fluency, word discovery and comprehension skills (see [20] and references within). Students also learn to self-monitor and eventually become more confident as their reading improves.

The opportunity to have on-going feedback from a dedicated listener is also potentially beneficial for readers, whether the listener is human or virtual [28]. With an automated tutor the young reader may feel more comfortable, less judged and may respond more favourably to being corrected by the machine. Thus the individual attention needed can be given with very little in the way of intervention from the teacher. Objective diagnostic reading tests can be developed that will allow for reading programmes to be individualised to each user based on the results of the diagnostic tests. The ability of ASR-based systems to facilitate two-way interaction can potentially elevate them above other computer-based literacy tutors (see for example, [17 and 20]). 
Finally, another benefit is that progress can be tracked using the stored outputs of each user's sessions with the tutor. This will allow for changes to be made as readers grow in confidence and skill, or if the programme is not having the desired effect. This kind of targeted intervention is difficult to achieve in the crowded classrooms of under-resourced schools.

\subsection{Challenges}

One important pedagogical challenge that needs to be addressed is how well this proposed system will integrate into a full literacy programme. ALTs are known to improve word recognition and reading fluency, but the ability to improve comprehension is less well documented. Nonetheless, if fluency improvement were the only benefit of ALTs, this would not diminish the utility of ASR-based literacy instruction. In fact, it has been shown that a fluent reader is better able to comprehend the meaning of a read passage as she is free from the cognitive burden of identifying words and can focus more directly on meaning [29].

However, the well-designed ASR-based literacy tutor is far more than a tool for increasing the fluency of a reader. Through the provision of interactive, pedagogically sound, reading instruction in the reader's primary mode of communication, ALTs are able to facilitate improvements in comprehension [21, 30]. Thus the proposed ALT has the capacity to augment the instruction received by readers in the traditional classroom setting. It may be even more beneficial for readers who are struggling, as there is opportunity for such readers to work at their own pace and not retreat to the background because of their own awareness of their deficit and the impact it can have on the rest of the reading group.

There is significant evidence that speech-based interaction provides for significantly higher learning gains than text-based interaction (see [31] for a review). However, there is less direct evidence of that relation when comparing the same modalities in ASR-based tutors. There are two studies known to the author that explore this systematically. In both [31] and [32], the effects that changing modality from text to speech would have on the learning of physics (and in the case of [32], computer literacy and critical thinking topics) were studied. The studies looked at changing modalities in both human and computer-based tutors. The main effect from both studies was that there was no difference between the gains in learning for either modality for the computer-based tutors, but a significant performance increase when the human tutor used speech. This would generally be taken as proof that the extra cost and computational complexity of ALTs could be avoided by using text-based tutors. However, this is not necessarily the case. D'Mello and Graesser suggested that the reason ASR-based tutors did not show a similar increase in learning is that they are not designed to take advantage of the cues that learners give, in a way that mimics human behaviour. They theorise that if the ASR-based tutors were to take advantage of paralinguistic features of speech, then the capacity to increase learning may be enhanced [32]. This suggestion has some merit. If the tutor is able to determine when the student is bored, frustrated or animated, then targeted intervention (or refraining from intervening) can be provided to enrich the process for the learner by retaining her attention and providing the reassurance needed. Studies have already adopted this approach, but are yet to be systematically assessed in order to determine their impact [33]. Given this important question, a significant component of assessing the utility of the Jamaican tutor will be systematic comparisons with non-ALT computer tutors.

ASR technology has matured in recent years, to the point where it is included in mainstream applications used on a day-to-day basis. In spite of these advances, there are still issues that require attention if it is to be successfully deployed in an ALT. For the Jamaican case, the two most significant among these issues are the overall robustness and accuracy of ASR and the availability of speech data recorded by speakers of Jamaican English.

The robustness of ASR systems is important when one considers that the tutor will be used in a noisy environment, which still poses a problem for the technology. If the accuracy of the ASR engine is low, then it may provide incorrect feedback to the reader, possibly leading to further frustration with the tool and a deficit in learning.

In the case of Jamaica there is need to pay careful attention to the actual errors made by the recogniser, as the Jamaican dialect influences the pronunciation of English words. For instance, where /o/ falls between two consonants in Standard English, speakers of the Jamaican dialect will substitute an /a/ - for example, 'pat' is routinely substituted for 'pot' [34]. If this type of error is not addressed, then the tool will in essence be reinforcing incorrect pronunciation, which will lead to difficulty in reading and comprehension.

One further challenge is the need for a corpus of Jamaican English spoken by children. In order for an ASR-based application to perform optimally, it must be trained using speech from the target population. Adaptation mechanism can be employed, but these invariably fail to work well for non-native or nontraditional native speakers. The issues here are related to cost and technical design. Recording can be 
costly, especially where the equipment has to be acquired. This aspect is already being addressed; a project is currently being undertaken, by the author, to collect such a corpus.

There are many accents on the island and one has to be careful that the candidates for recording are fluent in Jamaican Standard English. Such screening would not eliminate the necessary variety in the collected data, but will limit it in order to enhance the robustness of the speech models produced. Collection of a corpus of Jamaican English makes it possible to undertake further studies that go beyond the teaching of literacy into other areas of speech, hearing and language research.

\section{Conclusion}

The case has been made for using an ASR-based literacy tutor to increase rates of child literacy in Jamaica. This approach is mandated by the many challenges facing the students, teachers and administrators. It has been suggested that although it may be cheaper to employ currently available computerbased literacy tools, a tutor based on ASR technology with its ability to listen to the reader and respond where appropriate, would be more suited to the task. The benefits include one-on-one interaction, which goes some way to mimicking the experience of working with a dedicated human tutor. The proposed solution also offers the opportunity to develop a purpose-built system, rather than adapting a solution developed in an environment with different challenges and needs.

Though there are challenges to developing such a system, every effort must be brought to bear on the problem if there is to be a definitive response to the growing challenge of illiteracy in the near future. The potential benefits, such as increased confidence among children and the engagement of at risk groups, increased literacy and a population more prepared for long-term economic and human development make it worth the effort. Research done in other countries has shown that the improvement made by users of such systems is comparable to that made by other users tutored by human literacy experts. Thus, given the lack of resources needed for the expansive deployment of dedicated literacy experts in every school it is clear that the proposed solution is a viable alternative.

\section{Acknowledgements}

A shorter version of this paper appeared in IICE 2012.

\section{References}

[1] S. Coulombe, J.F. Tremblay, and S. Marchand, Literacy scores, human capital and growth across fourteen OECD countries (Cat. no. 89-552-MIE, no. 11), Statistics Canada, Ottawa, ON, 2004.

[2] UNESCO, Reaching the marginalized, Oxford University Press, Paris; Oxford, 2010.

[3] J. Cummins, Literacy, technology, and diversity: Teaching for success in changing times, Allyn and Bacon, Boston, MA, 2008.

[4] "Full literacy by 2015 - Education ministry outlines strategy.", Jamaica Gleaner. Retrieved from: http://jamaica-gleaner.com/gleaner/20110506/news/ news1 .html, May, 2011.

[5] Y.E. Lewis, Literacy in elementary school in Jamaica: The case of the grade four literacy test. Doctoral dissertation, University of Iowa, 2010.

[6] J. Helwig, C. Lambert and E. Marshall, Evaluation of the Expanding Education Horizons project: Recommendations for a new education activity to be included in USAID/Jamaica's strategy for 2010-2014, USAID, Kingston, Jamaica, 2008.

[7] UNDP, Human Development Report 2011: Sustainability and Equity: A Better Future for All, UNDP, New York, USA

[8] L. Douglas, Digicel Foundation literacy initiative reaping rewards, Jamaica Observer, March 2, 2012. Availble at http://www.jamaicaobserver.com/news/Digicel-Foundati on-literacy-initiative-reaping-rewards_10930300, Acessed: August 24, 2012.

[9] A.G. Bus, M.H. van Ijzenoorn and A.D. Pellegrini, "Joint bookreading makes for success in learning to read: A meta-analysis on intergenerational transmission of literacy.", Review of Educational Research, volume 65, 1995, pp. 1-21.

[10] R.H. Bradley, R.F. Corwyn, H.P. McAdoo and C.G. Coll, "The home environments of children in the United States part I: Variations by age, ethnicity, and poverty status.”, Child Development, volume 72, 2006, pp. 18441867.

[11] H. Raikes, B.A. Pan, G. Luze, C.S. Tamis-LeMonda, J. Brooks-Gunn and J. Constantine, et al., "Mother-child book reading in low-income families: Correlates and outcomes during the first three years of life." Child Development, volume 77, 2006, pp. 924-953.

[12] H. Blok, R. Oostdam, M. Otter \& M. Overmaat. "Computer-assisted instruction in support of beginning reading instruction: a review", Review of Educational Research, 72, 2009, pp.101-130. 
[13] U. Felix. "What do meta-analyses tell us about CALL effectiveness?", ReCALL, 17, 2005, pp. 269-288.

[14] J. Gamper, and J. Knapp. "A review of intelligent CALL systems", Computer Assisted Language Learning, 15, 2002, pp. 329-342.

[15] M. Eskenazi, "An overview of spoken language technology for education", Speech Communication, volume 51, 2009, pp . 832-844.

[16] M. McCandless, Word rejection for a literacy tutor, MIT. B.S. Thesis, 1992.

[17] J. Mostow, G. Aist, P. Burkhead, A. Corbett, A. Cuneo and S. Eitelman, et al., "Evaluation of an automated reading tutor that listens: Comparison to human tutoring and classroom instruction.", Journal of Educational Computing Research, volume 29, 2003, pp. 61-117.

[18] M.J. Russell, R.W. Series, L.J. Wallace, C.A. Brown and A. Skilling, "The STAR system: an interactive pronunciation tutor for young children.", Computer Speech and Language, volume 14 (2), 2000, pp. 161-175.

[19] Wise, B., R. Cole, S. van Vuuren, S. Schwartz, L. Snyder and N. Ngampatipatong, et al., "Learning to read with a virtual tutor: Foundations to literacy.", In C. Kinzer and L. Verhoeven (Eds.), Interactive literacy education: Facilitating literacy environments through technology, Mahwah, NJ: Lawrence Erlbaum, 2005, pp. 31-76.

[20] Adams, M.J., The promise of automatic speech recognition for fostering literacy growth in children and adults. In M. McKenna, L. Labbo, R. Kieffer and D. Reinking (Eds.), Handbook of Literacy and Technology (Vol. 2, pp. 109-128), Lawrence Erlbaum Associates, Hillsdale, NJ, 2005.

[21] J. Duchateau, Y.O. Kong, L. Cleuren, L. Latacz, J. Roelens and A. Samir et al., "Developing a reading tutor: design and evaluation of dedicated speech recognition and synthesis modules.", Speech Communication, volume 51(10), 2009, pp. 985-994.

[22] C. Cucchiarini, J. van Doremalen, and H. Strik, "DISCO: Development and Integration of Speech technology into Courseware for language learning.", Proceedings of Interspeech-2008, Brisbane, Australia, Sept. 26-29, 2008, pp. 2791-2794

[23] P. Cosi, R. Delmonte, S. Biscetti, R.A. Cole, B. Pellom, and S. Vuren, "Italian literacy tutor-tools and technologies for individuals with cognitive disabilities.", In Proceedings of the InSTIL/ICALL Symposium on Computer Assisted Learning, 2005.

[24] A. Kantor, M. Cernak, J. Havelka, S. Huber, J. Kleindienst and D.B. Gonzalez, "Reading Companion: The Technical and Social Design of an Automated Reading Tutor", In: Workshop on Child, Computer and Interaction, Portland, Oregon, U.S.A., 2012.
[25] X. Li, L. Deng, Y. Ju, and A. Acero, "Automatic children's reading tutor on hand-held devices.", In Proceedings Interspeech 2008, 2008, pp. 1733-1736.

[26] Allington, R. What really matters for struggling readers: Designing research-based programs. Pearson/Allyn and Bacon, Boston, 2006.

[27] Carneiro P. and J. Heckman, Human capital policy, In Inequality in America: What role for human capital policies?, MIT Press, Cambridge, MA, 2004, pp. 77-241.

[28] D. J. Chard, S. Vaughn and B.J. Tyler, "A synthesis of research on effective interventions for building reading fluency with elementary students with learning disabilities”, Journal of Learning Disabilities, 35, 2002, 386-406

[29] L.S. Fuchs, D. Fuchs, M.K. Hosp and J.R. Jenkins, "Oral reading fluency as an indicator of reading competence: A theoretical, empirical, and historical analysis", Scientific Studies of Reading, vol. 5, 2001, pp. 239-256.

[30] M.J. Adams, “Technology for Developing Children's Language and Literacy: Bringing Speech Recognition to the Classroom", The Joan Ganz Cooney Center at Sesame Workshop, New York, NY, 2011.

[31] D. Litman, C. Rose, K. Forbes-Riley, K. VanLehn, D. Bhembe and S. Silliman, "Spoken versus typed human and computer dialogue tutoring", International Journal of Artificial Intelligence In Education, volume 16(2), 2006, pp. 145-170.

[32] S.K. D'Mello, B.G. King, P. Chipman and A.C. Graesser, "Towards Spoken Human-Computer Tutorial Dialogues", Human-Computer Interaction, volume 25(4), 2010, pp. 289-323.

[33] M. Hasegawa-Johnson, S. E. Levinson, and T. Zhang Children's emotion recognition in an intelligent tutoring scenario. In Proceedings of Interspeech 2004, 2004, pp. 1441-1444.

[34] Pollard, V., From Jamaican Creole to Standard English: A handbook for teachers, The University of the West Indies Press, Kingston, Jamaica, 2003.

[35] M. Warschauer, Technological change and the future of CALL. In S. Fotos \& C. M. Moore (Eds.), New Perspectives on CALL for Second Language Classrooms, 2004, pp. 15-26.

[36] N. Gündüz. "Computer assisted language learning (CALL)", Journal of Language and Linguistic Studies, 1, 2005, pp. 193-214.

[37] B. Bloom, The 2-sigma problem: The search for methods of group instruction as effective as one-to-one tutoring. Educational Researcher, 13, 1984, pp. 4-16. 